\title{
LAND SURFACE TEMPERATURE CHANGE AFTER CONSTRUCTION OF THE KOZJAK DAM BASED ON REMOTE SENSING DATA
}

DOI: http://dx.doi.org/10.18509/GBP.2016.02

UDC: $627.82: 551.525 .2]: 528.85(497.782)$

\author{
MSc. Gordana JOVANOVSKA ${ }^{1}$ \\ Ass. Prof. Dr. Ugur AVDAN ${ }^{1}$ \\ Ass. Prof. Dr. Nalan DEMIRCIOGLU YILDIZ ${ }^{2}$ \\ Dr. Zehra YIGIT AVDAN ${ }^{3}$ \\ ${ }^{1}$ Earth and Space Sciences Institute/Anadolu University, Eskisehir - Turkey \\ ${ }^{2}$ Department of Landscape Architecture/Ataturk University, Erzurum - Turkey \\ ${ }^{3}$ Department of Environmental Engineering/Anadolu University, Eskisehir - Turkey
}

\begin{abstract}
Remotely sensed images are a resource for researches in wide study area. Based on thermal remote sensing technique, Land Surface Temperature (LST) changes analyses were made after construction the Dam of Kozjak near the capital of Republic of Macedonia. Two Landsat 5 remotely sensed images from 1984 and 2011, were used before and after construction of the dam, respectively. The LST of the images was automatically calculated by using LST retrieving tool in Erdas IMAGINE software. The analyses were made using zonal statistics within the boundaries of the previous created buffers of 100 meters, up to $1 \mathrm{~km}$ around the dam. The results showed that, the surroundings Land Surface Temperature values has decreased maximum $8.5^{\circ} \mathrm{C}$ and has also lowered the boundaries of the minimum, maximum and mean values of the region after the dam construction.
\end{abstract}

Keywords: Remote Sensing, Kozjak Dam, Land Surface Temperature LST, Landsat 5, Environment.

\section{INTRODUCTION}

Earth is subject to numerous ecological and environmental problems which have singular and combined effects that affect the physical and biological environment at all scales, from local to global. From the beginning of using satellite data, satellites have demonstrated that measurements of land cover advanced understanding of the spatial and temporal variability of many ecosystems and environmental conditions. There is a growing awareness among environmental scientists that remote sensing can and must play a role in providing the data needed to assess ecosystems conditions and to monitor change at all special scales [1].

The Landsat images, archived at Landsat receiving stations around the world, are a unique resource for global change research and application in agriculture, cartography, geology, forestry, regional planning, surveillance and education, and can be downloaded from the USGS `EarthExplorer' website. The Land Surface Temperature can be easily retrieved from the images.

Land Surface Temperature (LST) can be defined as a temperature of the land when touched with hands. LST provides an accurate measure for indicating energy exchange 
balance between the Earth and the atmosphere [2]. Using the thermal $\left(6^{\text {th }}\right)$ band from Landsat 5, LST can easily be retrieved and used in many areas, such as global climate change, hydrological, geo/biophysical, urban land use/land cover etc.

Land cover and environmental changes are expected with a dam construction. The presence of a water area can change the whole ecosystem for better or for worse. In this study area an attempt for catching the LST changes that happened after the construction of the Kozjak Dam. This study is supposed to answer the question, how does the dam influence on its surrounding land surface temperature values and the answer should be useful for environmental and ecological problems.

\section{DATA AND METHODS}

\section{Study area}

The Kozjak Dam or the multipurpose hydropower plant of Kozjak is located approximately $25 \mathrm{~km}$ south west of the capital of Republic of Macedonia, Skopje (Figure 1). Kozjak was constructed on Treska River, right tributary of Vardar River. The construction of the dam started in August 1994 and in May 2003 reservoir's first filling has started and finally in July 2004 the first, and in September 2004 the second generator of the powerhouse was set in operation [3].

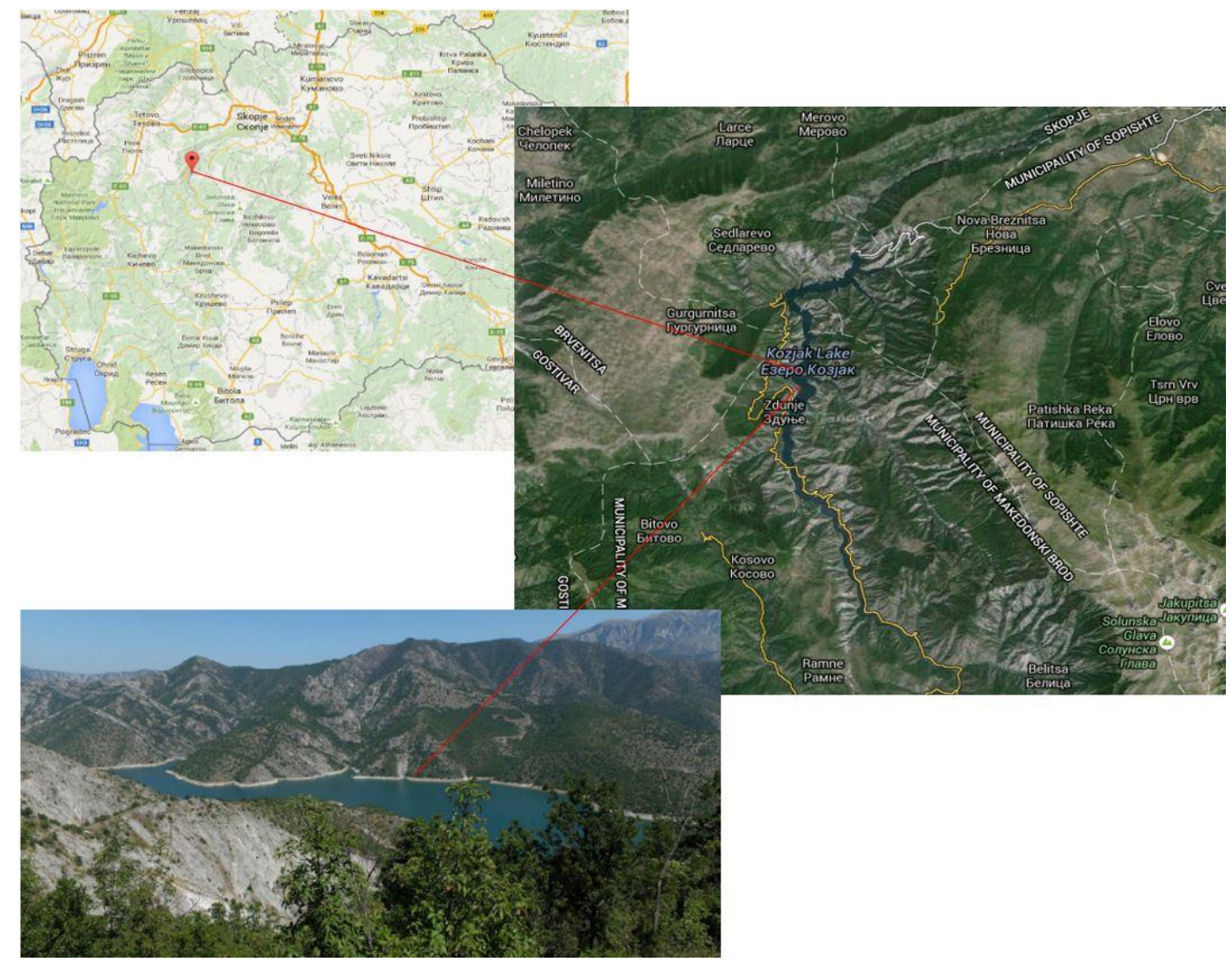

Figure 1. Kozjak Dam`s location (pictures are taken from Google Maps)

The Kozjak Dam/reservoir is a key-structure of the multipurpose hydraulic scheme with the main task flood control, with retention storage of $100 \times 10^{6} \mathrm{~m}^{3}$, serves for electricity production $152 \times 10^{6} \mathrm{kWh}$ per year, as well it will be used for water-supply in future. 
The total reservoir volume is 550 million $\mathrm{m}^{3}$, formed by the earth-rock Kozyak dam, the highest in Republic of Macedonia with $114 \mathrm{~m}$ above the terrain and $130 \mathrm{~m}$ above the foundation [4]. According to [4] the analyses for the environmental impact and the assessment are rather positive due to the location of dams and applied technical solutions.

\section{Landsat Data and Land Surface Temperature Calculation}

Two cloud-free Landsat 5 images were downloaded from the USGS webpage. The images were collected on July 1, 1984 and July 12, 2011. These dates were chosen since there is not much difference between them, both of the images were cloud free and the dates are appropriate for the planed analysis, first image is before and second image is after the finishing of the construction of the Kozjak dam (2004) (Figure 2).

The Landsat 5 Thematic Mapper (TM) images have pixel size of $30 \times 30 \mathrm{~m}$ for all bands except the thermal band with a pixel size of $120 \times 120 \mathrm{~m}$ but is resampled to 30 -meter pixel [5]. With the use of the thermal band, the LST was retrieved. The LST was retrieved in Erdas IMAGINE following the model as suggested in [6] using the emissivity and NDVI (Normalized Difference Vegetation Index) values. After the LST was retrieved, the study area was selected and around the area ten $100 \mathrm{~m}$ ring buffers in ArcGIS were created. Then, to all the areas zonal statistics were made and the results were compared.
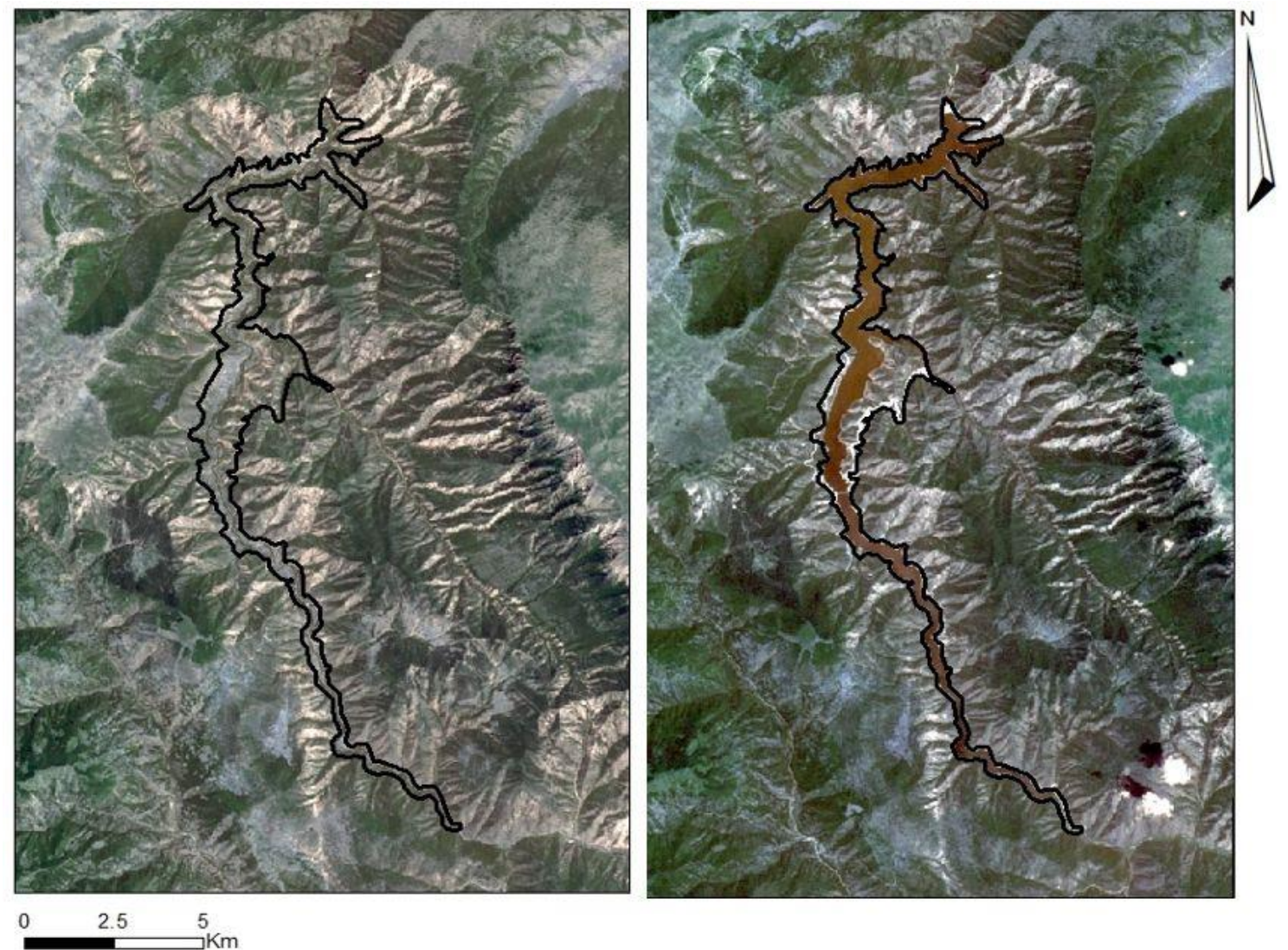

Figure 2. Landsat 5 images, 1984 (left) and 2011 (right). The black line represents the study area.

\section{Methods}

The differences between previously retrieved LST maps is supposed to show the changes that happened after the construction of the Kozjak dam. For fetching the changes, the 
boundary of the dam was drawn. Over the boundary buffers up to 1 kilometer, with 100 $\mathrm{m}$ distance were geo-processed in ArcGIS (Figure 3). The Zonal Statistics as Table geoprocessing tool are calculating statistics from a raster (the LST maps) within zones from a vector layer, in this case the buffer zones. Within the buffer zones, zonal statistics were made, giving the maximum, minimum, mean etc. values of the areas. Comparison from the zonal statistics for the both years were made and are represented in the results section.
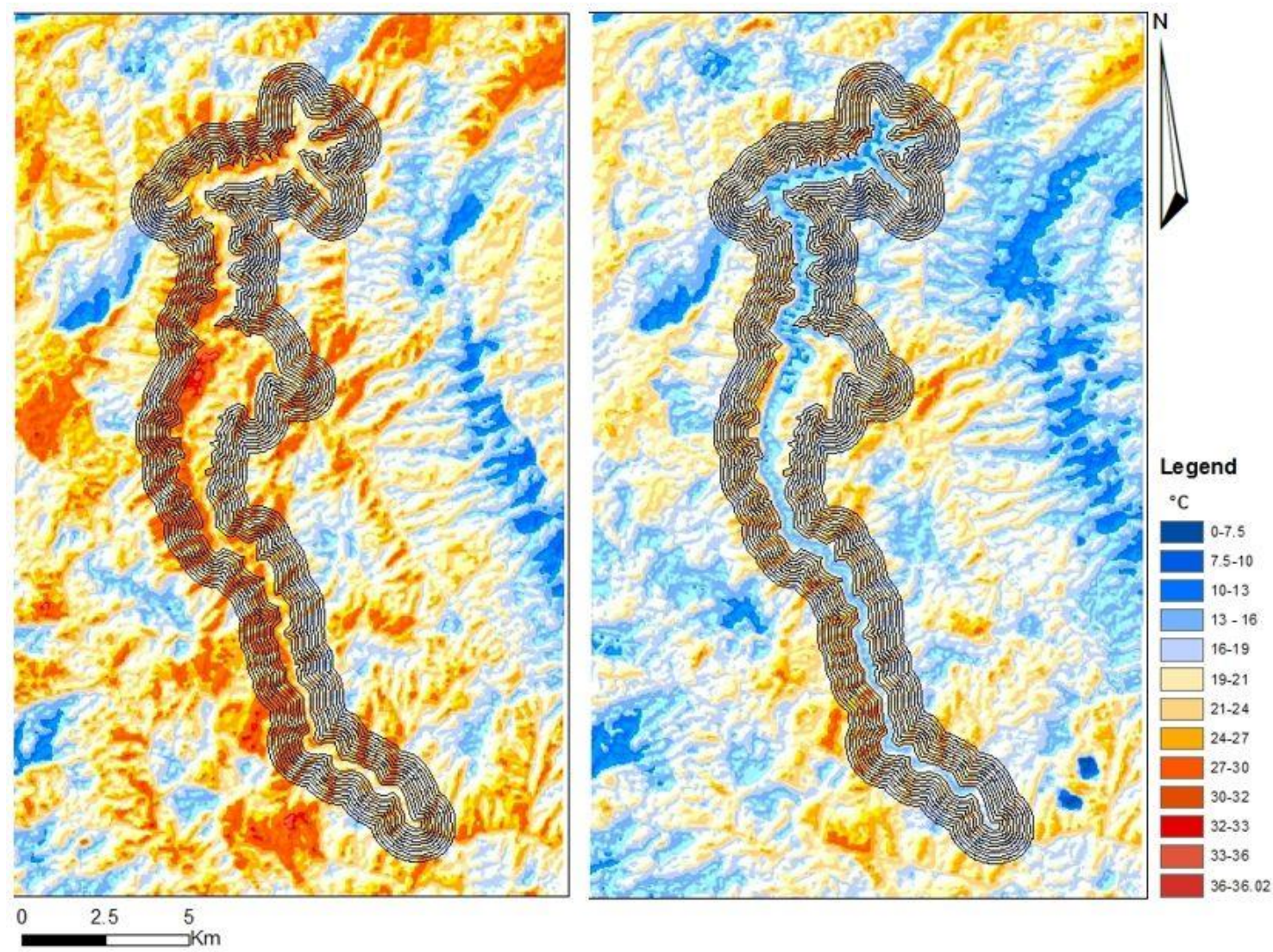

Figure 3. Landsat 5 LST images, 1984 (left) and 2011 (right). The black lines represents the study areas.

\section{RESULTS AND DISCUTION}

\section{Zonal Statistics Results}

Among 11 studied areas (the dam area and the 10 buffers of 100 meters), the biggest changes were observed in the dam area as expected. The biggest difference has been noticed in the maximum temperatures, up to $8.5^{\circ} \mathrm{C}$ in the borders of the dam area. The mean values has shown differences of $7.4{ }^{\circ} \mathrm{C}$ as a maximum value. In the dam area the difference for the minimum value has been noticed to be $4.2{ }^{\circ} \mathrm{C}$ maximum value. The differences in the buffer zones starts from $4.1^{\circ} \mathrm{C}$ in the $100 \mathrm{~m}$ area and goes until $2.9^{\circ} \mathrm{C}$ in the $1000 \mathrm{~m}$ area. The biggest differences are noticed in the values of the maximum temperatures (Table 1).

Table 1. Differences between the LST values from 1984 and 2011 from the Zonal Statistics result.

\begin{tabular}{|c|c|c|c|c|c|}
\hline Area & Min & Max & Range & Mean & SD \\
\hline Dam area & 4.20 & 8.53 & 4.33 & 7.37 & -0.10 \\
\hline
\end{tabular}




\begin{tabular}{|c|c|c|c|c|c|}
$100 \mathrm{~m}$ buffer & 1.86 & 4.10 & 2.25 & 3.32 & 0.76 \\
\hline $200 \mathrm{~m}$ buffer & 1.84 & 2.86 & 1.02 & 2.47 & 0.83 \\
\hline $300 \mathrm{~m}$ buffer & 0.92 & 3.27 & 2.35 & 2.34 & 0.78 \\
\hline $400 \mathrm{~m}$ buffer & 0.93 & 2.88 & 1.95 & 2.25 & 0.79 \\
\hline $500 \mathrm{~m}$ buffer & 0.93 & 3.70 & 2.77 & 2.20 & 0.82 \\
\hline $600 \mathrm{~m}$ buffer & 0.93 & 3.28 & 2.36 & 2.20 & 0.77 \\
\hline $700 \mathrm{~m}$ buffer & 0.46 & 2.47 & 2.01 & 2.18 & 0.79 \\
\hline $800 \mathrm{~m}$ buffer & 0.46 & 3.30 & 2.84 & 2.18 & 0.70 \\
\hline $900 \mathrm{~m}$ buffer & 0.93 & 3.29 & 2.36 & 2.21 & 0.64 \\
\hline $1000 \mathrm{~m}$ buffer & 0.47 & 2.89 & 2.42 & 2.26 & 0.69 \\
\hline
\end{tabular}

Comparing the results from the Zonal Statistics and observing them graphically, it is clear that the boundaries from the minimum, maximum and mean values has been changed to a lower level. The biggest difference can be seen in the maximum values (Figure 4).

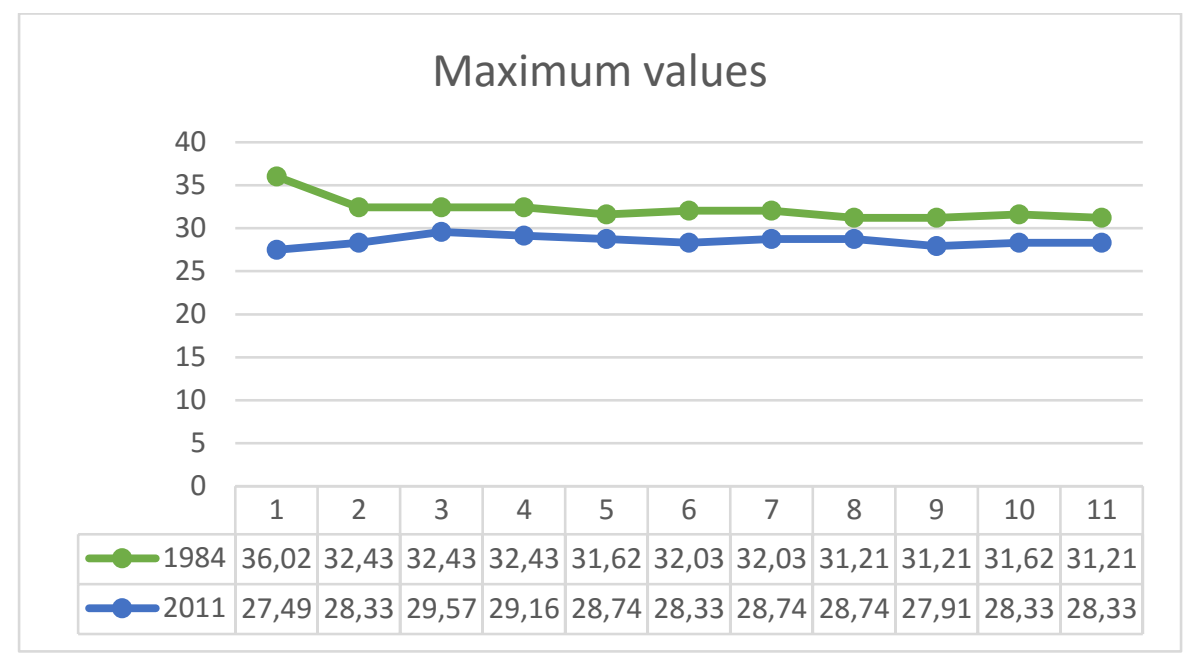

Figure 4. Differences between the maximum LST values from the zonal statistics from July 1, 1984 and July 12, 2011.

\section{DISCUSSION}

Many studies have shown that the way of using and changing an area affects the surface temperature [7], [8], [9]. Other studies [10] have shown that the water surface area is colder in comparison with the other surface types. In this study, after retrieving the LST of the study area, we aimed to determine the effects of the water on the valley by throwing ten 100 meter buffer zones. Temperature maps show that water area have effect of climatic elements of the land surface temperature around the water body. With the change of the temperature, the flora and fauna are also under affection, positive or negative and that bring significant influence in the environment. For the atmospheric system, temperature, variations in moisture percentage of air caused by the big water body differentiate microclimate related to region topography. Additionally, regional scaled climatic changes can be observed [11].This type of studies should be taken in consideration by local government in taking proper decisions when it comes to nature. 


\section{REFERENCES:}

[1] Ustin, S., Manual of Remote Sensing: Remote sensing for natural resource management and environmental monitoring. 2004: Wiley Hoboken, NJ, USA.

[2] Zhengming, W. and J. Dozier, Land-surface temperature measurement from space: Physical principles and inverse modeling. Geoscience and Remote Sensing, IEEE Transactions on, 1989. 27(3): p. 268-278.

[3] Mihajlovski, S. and B. Dimitrievska, Hydro power plant "Kozjak", a key water management system of future optimum development for the capital Skopje. Dams and Reservoirs, Societies and Environment in the 21st Century, Vols 1 and 2, 2006: p. 373376.

[4] Tanchev, L. and L. Petkovski, Dam Engineering In Republic Of Macedonia: Recent Practice And Plans.

[5] http://landsat.usgs.gov/, 2014.

[6] Sobrino, J.A., J.C. Jimenez-Munoz, and L. Paolini, Land surface temperature retrieval from LANDSAT TM 5. Remote Sensing of Environment, 2004. 90(4): p. 434-440.

[7] Eliasson, I. and M.K. Svensson, Spatial air temperature variations and urban land use - a statistical approach. Meteorological Applications, 2003. 10(2): p. 135-149.

[8] Chen, X.L., et al., Remote sensing image-based analysis of the relationship between urban heat island and land use/cover changes. Remote Sensing of Environment, 2006. 104(2): p. 133-146.

[9] Zhou, W.Q., et al., Relationships between land cover and the surface urban heat island: seasonal variability and effects of spatial and thematic resolution of land cover data on predicting land surface temperatures. Landscape Ecology, 2014. 29(1): p. 153-167.

[10] Yıldız Demircioglu N., A.U., Yilmaz S., Dagliyar A., Matzarakis A., Thermal Band Analysis of Different Land Uses in Urban Spaces and its Effects on Bioclimatic Comfort. 3rd Int. Conf. on Countermeasures to Urban Heat Island., 2014.

[11] Tahmiscioğlu, M. Sait, et al. "Positive and negative impacts of dams on the environment." International Congress on River Basin Management. 2007. 


\title{
LANDSCAPE DIVERSITY, TYPES AND HOTSPOTS OF SLOVENIA
}

\author{
DOI: http://dx.doi.org/10.18509/GBP.2016.03
}

UDC: 911.52(497.4)

\author{
Dr. Drago Perko \\ Dr. Rok Ciglič \\ Dr. Matija Zorn
}

Anton Melik Geographical Institute Research Centre of the Slovenian Academy of Sciences and Arts, Slovenia

\begin{abstract}
Due to its position at the intersection of the Mediterranean, Alps, Dinaric Alps, and Pannonian Basin, Slovenia is considered one of the most diverse countries in Europe. Based on digital data on relief, rock, and vegetation-the most significant elements of the internal structure of Slovenian landscapes and at the same time of their external appearance-a geographic information system was used to determine the natural landscape diversity and landscape hotspots of Slovenia and its municipalities. Landscape hotspots are defined as areas with the highest landscape diversity, which offers some advantages as well as some disadvantages and challenges to certain municipalities.
\end{abstract}

Keywords: geography, landscape diversity, landscape hotspot, municipality, Slovenia

\section{INTRODUCTION}

Because of Slovenia's location at the intersection of the Mediterranean, Alps, Dinaric Alps, and Pannonian Basin [1], landscape diversity can be regarded as one of the country's natural resources. Diversity can be viewed as a development opportunity on the one hand, but on the other it may create specific challenges for spatial planning. Municipalities with greater landscape diversity and many landscape hotspots can accelerate their economic development because of their attractiveness for tourism or the availability of various natural resources. However, high diversity can also limit the space available for various economic activities, prevent large-scale agricultural production, increase the risk of various natural disasters, and prevent the transfer of good practices from one area to another.

This article analyzes the natural heterogeneity of Slovenia and presents some of the first results of the research project Landscape Diversity and Hotspots of Slovenia. The main goal of this project is to define areas with a similar level of heterogeneity, which is reflected in landscape diversity, and to locate the landscape hotspots of Slovenia as the areas with the highest landscape diversity using a relatively objective method.

Based on descriptions by various authors [2], [3], [4], [5], [6], it is possible to divide the analysis of landscape diversity in the following manner. Diversity or heterogeneity of landscape can be analyzed using categorical and/or numerical data. Complexity refers to a qualitative or categorical description and variability refers to a quantitative or numerical description of a landscape. Complexity (also termed structure) consists of composition (also termed diversity, landscape diversity, or richness) and configuration (also termed pattern or spatial configuration). 